\title{
F CASE Study: Control of respiratory disease in male Holstein calves with tildipirosin and effect on health and growth from 0 to 4 months of age
}

\author{
T. M. Hill, ${ }^{1}$ J. D. Quigley, F. X. Suarez-Mena, PAS, T. S. Dennis, and R. L. Schlotterbeck \\ Nurture Research Center, Provimi, Brookville, OH 45309
}

\begin{abstract}
In trial 1, phase 1, 48 male Holstein calves initially 2 to $4 \mathrm{~d}$ of age were transported $3.5 \mathrm{~h}$ to the research facility. Calves were randomly selected to either receive a s.c. injection of Zuprevo (Merck Animal Health, Summit, NJ; $4 \mathrm{mg}$ of tildipirosin $/ \mathrm{kg}$ of BW; TIL) the day after arrival (d 0) and again at weaning (d 42) or receive no injections $(\mathrm{CON})$. Calves were fed $0.66 \mathrm{~kg}$ of milk replacer DM daily for $39 \mathrm{~d}$ and then $0.33 \mathrm{~kg}$ daily for $3 \mathrm{~d}$. A starter was fed free choice for the $56 \mathrm{~d}$ of phase 1 . In trial 1 , phase 2 , the same calves from phase 1 grouped by CON and TIL were moved to group pens (4 pens per treatment, 4 calves per pen) for the next $56 \mathrm{~d}$. The starter was blended with $5 \%$ chopped grass hay and fed free choice. Trial 2 was similar to trial 1, phase 2 and used 48 two-month-old male Holstein calves. Calves were randomly selected to receive either a s.c. injection of Zuprevo (4 $\mathrm{mg}$ of tildipirosin $/ \mathrm{kg}$ of $\mathrm{BW}$; TIL) on d 0 or no injections (CON). In trial 1, phase 1, preweaning ADG and BCS change; postweaning starter intake and hip width change; overall starter intake, ADG, and hip width change; final hip width; and final BCS were greater for TIL than CON. During phase 2 of trial 1 and trial 2, calf ADG and hip width change were greater for TIL than CON. Overall, in transported Holstein calves, TIL improved ADG and structural growth by approximately $13 \%$.
\end{abstract}

Key words: dairy calf, antibiotics, pneumonia, medication

\section{INTRODUCTION}

Respiratory infections are of significant concern in dairy calves $>1$ mo of age (Svensson et al., 2003) and are the primary cause of mortality after weaning (USDA-APHIS, 2009). Stanton et al. (2010) reported improvements in calf growth with metaphylactic treatment of relatively healthy calves with tulathromycin (TUL). Stanton et al. (2010, 2012, 2013) also reported that metaphylactic use of TUL

The authors declare no conflict of interest.

${ }^{1}$ Corresponding author: mhill@provimi-na.com in commingled dairy calves reduced the incidence of diarrhea, otitis media, and bovine respiratory disease complex compared with either metaphylactic treatment with oxytetracycline or no antibiotic treatment.

Tildipirosin (TIL) is an antibiotic approved for control of respiratory disease in cattle at high risk of developing bovine respiratory disease, and it may remain in lung tissue for up to $28 \mathrm{~d}$ (Menge et al., 2012). Tulathromycin and TIL are reported to have good efficacy to reduce issues with respiratory pathogens in dairy calves less than 3 mo of age (Amrine et al., 2014; Confer et al., 2016; Bartram et al., 2016). Amrine et al. (2014) and Bartram et al. (2016) reported that calf ADG after Mannheimia haemolytica or Mycoplasma bovis challenges were greater in calves treated with both TIL and TUL compared with non-antibiotic-treated calves. Although government agencies encourage less use of antibiotics in livestock (Weese et al., 2015), proper metaphylactic use of antibiotics in livestock might lower the overall use of antibiotics and reduce the risk of antibiotic resistance (Weese, 2006). Additionally, metaphylactic antibiotic treatments of dairy calves are implemented on many farms (USDA-APHIS, 1999).

Therefore, with the successful use of TUL and TIL to reduce respiratory sickness common in pre- and postweaned dairy calves and improved growth in calves treated with TUL in some studies, research was implemented to test the metaphylactic use of TIL in pre- and postweaned dairy calves.

\section{MATERIALS AND METHODS}

Calves were cared for by acceptable practices as described in the Guide for the Care and Use of Agricultural Animals in Agricultural Research and Teaching (FASS, 2010). In phase 1 of trial 1, 48 male Holstein calves initially 2 to $4 \mathrm{~d}$ of age from a single dairy farm were transported $3.5 \mathrm{~h}$ to the Nurture Research Center in southwest Ohio. Upon arrival, calves were randomly selected to either receive a s.c. injection of Zuprevo (Merck Animal Health, Summit, NJ; $4 \mathrm{mg}$ of tildipirosin/kg of BW; TIL) the day after arrival (d 0) and again at weaning (d 42) or receive no injections $(\mathbf{C O N})$. Calves were housed in $1.2 \mathrm{~m} \times 2.4 \mathrm{~m}$ individual pens with a coarse rock, tile-drained floor bedded with straw in a curtain-sided, naturally ventilated barn with no 
Table 1. Analyzed nutrient composition of diets fed

Trial 1

Feed, \% DM basis unless otherwise indicated

DM, \% as fed
CP
Fat
ADF
NDF
Sugar
Starch
Ash
Calcium
Phosphorus

\begin{tabular}{ccccccc}
\hline & & & & \multicolumn{2}{c}{ Trial 2 } \\
\cline { 6 - 6 } \cline { 5 - 6 } Milk replacer & Starter & Hay & & Starter & Hay \\
\hline 96.3 & 88.6 & 87.1 & & 87.3 & 86.1 \\
25.5 & 19.3 & 12.6 & & 20.3 & 9.1 \\
18.7 & 3.6 & 1.9 & & 4.1 & 21.6 \\
- & 31.9 & 44.8 & & 7.9 & 43.4 \\
- & 46.3 & 68.1 & & 16.1 & 67.9 \\
- & 5.3 & 3.5 & & 5.1 & 9.4 \\
- & 8.0 & 1.4 & & 40.4 & 1.3 \\
5.5 & 6.7 & 9.9 & & 5.7 & 8.9 \\
0.67 & 1.01 & 0.47 & & 0.74 & 0.37 \\
0.64 & 0.56 & 0.32 & & 0.53 & 0.29
\end{tabular}

added heat for $56 \mathrm{~d}$. A milk replacer was fed at $0.66 \mathrm{~kg}$ of DM daily for $39 \mathrm{~d}$ and then $0.33 \mathrm{~kg}$ of DM daily for $3 \mathrm{~d}$. The milk replacer manufactured with whey, whey protein concentrate, and animal fat (25\% CP, $18 \%$ fat; Table 1) was reconstituted to $14 \%$ solids with warm water and fed at 0630 and $1400 \mathrm{~h}$ daily. A low-starch, pelleted starter similar to the one fed by Hill et al. (2016) and water were fed free choice for the $56 \mathrm{~d}$ of phase 1 . Every other bag of milk replacer and starter was sampled and composited for nutrient analysis (Table 1). Management practices including vaccinations and medical treatments during the trial were based on the recommendations of the herd veterinarian.

The day after arrival at approximately noon, the calves were weighed (d 0, initial BW). At this time, blood was sampled intravenously, serum was separated by centrifugation at $3,000 \times g\left(\mathrm{VWR}\right.$, Batavia, IL) at $20^{\circ} \mathrm{C}$ for 15 min, and serum protein concentration was estimated using an optical refractometer (ATAGO U.S.A. Inc., Bellevue, WA).

Feces were scored daily using a 1-to-5 scale with 1 being normal and 5 being watery (modified from Kertz and Chester-Jones, 2004). Calves with fecal scores of 3 or greater (considered abnormal fecal scores) received oral electrolytes that were not counted as medical treatments. During the first $28 \mathrm{~d}$, the first abnormal feces (fecal score of 3 or greater) per calf was sampled and mixed. An aliquot was tested for Cryptosporidium, Rotavirus, Coronavirus, or K99 Escherichia coli using lateral immunochromatography strips (Biox Diagnostics, Jemelle, Belgium). Antibiotic medical treatments were recorded daily. Baytril 100 (Bayer Healthcare, Shawnee Mission, $\mathrm{KS} ; 5 \mathrm{~mL}$ subcutaneously) was administered for coughing, nasal discharges, labored breathing, and rectal temperatures $>39.4^{\circ} \mathrm{C}$. Navel infections were treated with $5 \mathrm{~mL}$ of penicillin G procaine (300,000 units/mL; Agri Laboratories LTD, St. Joseph, MO) intramuscularly daily for 7 d. On d 28, 42, and 56, an experienced technician used a stethoscope to listen for abnormal sounds associated with breathing (right, anterior side of the calf) to further assist in identification of respiratory disease.

Calves received an intranasal tissue sensitive respiratory disease vaccine (TSV-2, Zoetis, Exton, PA) and s.c. injections of vitamins A, D, and E (Vital E - A + D, Stuart Products, Bedford, TX) and Se (MU-SE, Merck Animal Health) upon arrival. Calves received an injection of Bovashield Gold 5 (Zoetis) at d 7 and again at d 28. Calves were castrated and dehorned at $36 \mathrm{~d}$ of age.

Calves were weighed initially and weekly thereafter. Body condition score (1 being thin and 5 being obese, modified from Wildman et al., 1982) and hip width using a caliper were measured initially and every 2 wk thereafter.

In phase 2 of trial 1 , the same calves from phase 1 grouped by CON and TIL were moved to group pens $(6$ pens per treatment with 4 calves per pen) for the next 56 d. The pens had $6.5 \mathrm{~m}^{2}$ of outside pen space and $1.35 \mathrm{~m}^{2}$ of inside pen space per calf. Inside pen space was bedded with straw, and there was no added heat. The same starter fed in phase 1 was blended with $5 \%$ chopped grass hay (Table 1) and fed with water free choice. Every other bag of starter and every bale of hay was sampled and composited for nutrient analysis. Calves were weighed, scored for body condition, and measured for hip width initially and at 28 and $56 \mathrm{~d}$ of phase 2 .

The average ambient temperature in trial 1 , phase 1 was $10^{\circ} \mathrm{C}$ with a range from -4 to $28^{\circ} \mathrm{C}$. The average relative humidity was $75 \%$ with a range from 20 to $100 \%$. The average ambient temperature in trial 1 , phase 2 was $21^{\circ} \mathrm{C}$ with a range from 4 to $33^{\circ} \mathrm{C}$. The average relative humidity was $70 \%$ with a range from 20 to $100 \%$.

In trial 2 (56 d in length), 48 Holstein calves that were 2 mo of age $(71.2 \pm 1.73 \mathrm{~kg}$ of $\mathrm{BW})$ were randomly selected to either receive a s.c. injection of tildipirosin (TIL; Zuprevo, Merck Animal Health) at $4 \mathrm{mg} / \mathrm{kg}$ of BW or receive no injection $(\mathrm{CON})$. Calves had been previously transported $3.5 \mathrm{~h}$ and managed as in phase 1 of trial 1 . Calves had been weaned for 2 wk when trial 2 began. Feeding and 
management of the calves were as in phase 2 of trial 1 with calves in 12 pens ( 4 calves per pen). The starter was a high-starch, textured feed blended with $5 \%$ chopped grass hay with a similar composition as fed by Hill et al. (2016; Table 1). The average ambient temperature in trial 2 was $22^{\circ} \mathrm{C}$ with a range from 10 to $33^{\circ} \mathrm{C}$. The average relative humidity was $84 \%$ with a range from 22 to $100 \%$.

Composites of feeds, refused feed, and feces were analyzed as described by Hill et al. (2016). Nutrient analysis of the refused feed for each wk and pen resembled the feed offered.

In phase 1 of trial 1 , data were first grouped by wk, except hip width and BCS change, which were grouped by $14-d$ periods. The data were analyzed as a completely randomized design with repeated measures when applicable by Proc Mixed in SAS (version 8, SAS Institute Inc., Cary, $\mathrm{NC}$ ). An auto-regressive type 1 covariance matrix was employed as determined using Akaike's information criteria. Exceptions were abnormal fecal score days and medical days, which were summed over the entire phase and analyzed using Kruskal-Wallis test with Proc NPAR1WAY in SAS. Calf (one calf per pen) was the experimental unit. In phase 2 of trial 1 and trial 2, intake and growth data were analyzed as a completely randomized design with repeated measures when applicable (grouped in two 28-d segments for body measurements) by Proc Mixed in SAS. An auto-regressive type 1 covariance matrix was employed as determined using Akaike's information criteria. Pen was the experimental unit. Significance was determined at $P \leq 0.05$.

\section{RESULTS AND DISCUSSION}

Initial measurements did not differ in phase 1 of trial 1 (Table 2). Preweaning ADG (0.47 vs. $0.55 \mathrm{~kg} / \mathrm{d}$ ) and BCS change were greater $(P<0.03)$ for TIL than CON (Table 2). Postweaning starter intake $(0.33$ vs. $0.44 \mathrm{~kg} / \mathrm{d})$ and hip width change $(1.7$ vs. $2.0 \mathrm{~cm})$ were greater $(P$ $<0.05)$ for TIL than CON. Overall starter intake, ADG ( 0.57 vs. $0.65 \mathrm{~kg} / \mathrm{d})$, hip width change $(4.0$ vs. $4.5 \mathrm{~cm})$, final hip width, and final BCS were greater $(P<0.04)$ for TIL than CON. Number of medical treatments did not differ between treatments. For CON, there were 5 calves treated for navel infections and 3 calves treated for nasal discharges, and these 3 calves were re-treated a day later for fever during the preweaning period. During the postweaning period there was an additional calf treated for nasal discharge. For TIL, there were 4 calves treated for navel infections and 2 calves treated for nasal discharge. One of the calves treated for nasal discharge was treated a day later for fever. All navel infections were identified and treatments began on d 0 . No abnormal breathing sounds were detected using the stethoscope on d 28,42 , and 56 . Abnormal fecal score did not differ between treatments. All feces from calves with abnormal feces tested positive for Cryptosporidium, Rotavirus, or both organisms. Dur- ing phase 2 of trial 1, calf ADG (0.86 vs. $0.99 \mathrm{~kg} / \mathrm{d}$ ), hip width change ( 4.1 vs. $4.6 \mathrm{~cm})$, final hip width, and final BCS were greater $(P<0.05)$ for TIL than CON (Table 3$)$. During phase 1, the overall increase in BW and hip width gain from treating with TIL was 12 to $13 \%$ greater compared with CON. During phase 2, the overall increase in BW and hip width gain from treating with TIL was 12 to $15 \%$ greater compared with CON. Over the $112 \mathrm{~d}$ of both phases, TIL calves gained $11.8 \mathrm{~kg}(14 \%)$ more BW $(80.0$ vs. $91.8 \mathrm{~kg})$ and gained $1.0 \mathrm{~cm}(13 \%)$ more hip width $(9.1$ vs. $8.1 \mathrm{~cm}$ ) than $\mathrm{CON}$ calves.

In trial 2, initial measurements did not differ (Table 3). No calves were treated for any sickness during the trial. Calf ADG (0.84 vs. $0.95 \mathrm{~kg} / \mathrm{d}$ ), feed efficiency (0.29 vs. $0.32 \mathrm{G}: \mathrm{F})$, and hip width change $(4.1$ vs. $4.8 \mathrm{~cm})$ were greater $(P<0.04)$ for calves treated with TIL than CON (Table 3). Over the 56-d trial, TIL calves gained $6.2 \mathrm{~kg}$ more BW and $0.7 \mathrm{~cm}$ more hip width than CON calves.

Viruses allow for bacterial colonization of the lungs and are a typical reason for the onset of respiratory disease in beef calves (Yates, 1982). Stressors are a trigger of disease in calves through their effect on cortisol and various cytokines (Hulbert and Moisá, 2016). Stressors can be present the majority of days during the first 2 mo of a dairy calf's life (Hulbert and Moisá, 2016). Calves in the current trial faced many stressors including a 3.5 -h transport from their birth farm to the research facility, several vaccinations, castrating, dehorning, weaning, and commingling. We expected to treat more calves for respiratory disease than we did based on treatment rates of groups of calves in our research facility over the prior year. We speculate that there was some level of respiratory disease in the calves that we did not identify and treat. Use of TIL may have reduced the incidence of subclinical respiratory disease and allowed for increased growth.

Calves in the current trials appeared relatively healthy based on the few illnesses that were identified. In trial 1 , phase 1, 6 of 48 calves were treated for some type of nasal discharge or fever that appeared to be related to respiratory infection. Navel infections in 9 calves on d 0 were evenly distributed between CON and TIL calves. Six of the 9 calves with navel infections did not have iodinestained hair around their navels, whereas calves without navel infections showed staining; thus, source-farm personnel may have not properly dipped their navels with iodine solution at birth. No calves were treated for any sickness during phase 2 of trial 1.

Amrine et al. (2014) reported that the ADG of feeder calves (178 $\pm 19.7 \mathrm{~kg}$ of BW) after a Mannheimia haemolytica challenge were increased in calves treated with both TIL and TUL compared with non-antibiotic-treated calves. Bartram et al. (2016) reported that the ADG of 10to 28-d-old dairy calves after a Mycoplasma bovis challenge were increased when treated with both TIL and TUL compared with non-antibiotic-treated calves. In these studies, many of the calves were sick with disease caused by 
the challenge organism. Stanton et al. (2010) and Hill et al. (2017) reported improvements in calf growth with metaphylactic treatment of relatively healthy calves with TUL. Stanton et al. (2010, 2012, 2013) also reported that metaphylactic use of TUL in commingled dairy calves lowered the incidence of diarrhea, otitis media, and bovine respiratory disease complex compared with either metaphylactic treatment with oxytetracycline or no antibiotic treatment; however, growth was not changed with the use of TUL in calves that were sick. They attributed improvements in growth to reduction of disease in the calves.

In our trials, calves treated with TIL gained approximately $13 \%$ more BW and hip width than CON from 3 d to 4 mo of age. With a similar design and relatively healthy dairy calves, treatment with TUL increased BW and hip width gain approximately $8 \%$ compared with

Table 2. Performance of calves from 0 to $56 \mathrm{~d}$ that had not been treated (CON) or had been treated (TIL) with Zuprevo ${ }^{1}$ (4 mg of tildipirosin/kg of BW) near birth and weaning (42 d apart) in trial 1 , phase 2

\begin{tabular}{|c|c|c|c|c|}
\hline Item & CON & TIL & SEM & $P$-value \\
\hline Initial serum protein, $\mathrm{mg} / \mathrm{dL}$ & 5.5 & 5.5 & 0.15 & 0.99 \\
\hline Initial BW, kg & 42.2 & 41.9 & 1.47 & 0.86 \\
\hline Final BW, $\mathrm{kg}$ & 74.3 & 78.4 & 2.64 & 0.14 \\
\hline Initial hip width, cm & 17.2 & 17.3 & 0.25 & 0.93 \\
\hline Final hip width, cm & 21.2 & 21.8 & 0.27 & 0.04 \\
\hline Initial BCS ${ }^{2}$ & 2.2 & 2.2 & 0.037 & 0.58 \\
\hline Final BCS & 2.3 & 2.4 & 0.047 & 0.02 \\
\hline \multicolumn{5}{|l|}{ Preweaning ( 0 to $42 \mathrm{~d}$ ) } \\
\hline Milk replacer intake, kg/d & 0.63 & 0.63 & - & - \\
\hline Starter intake, $\mathrm{kg} / \mathrm{d}$ & 0.33 & 0.44 & 0.070 & 0.12 \\
\hline$A D G, k g / d$ & 0.47 & 0.55 & 0.030 & 0.02 \\
\hline Feed efficiency ${ }^{3}$ & 0.462 & 0.492 & 0.0247 & 0.22 \\
\hline Hip width change, $\mathrm{cm}$ & 2.3 & 2.6 & 0.21 & 0.22 \\
\hline BCS change & 0.1 & 0.3 & 0.06 & 0.03 \\
\hline Fecal score $^{4}$ & 2.2 & 2.2 & 0.02 & 0.71 \\
\hline Abnormal fecal days ${ }^{5}$ & 2.0 & 2.3 & 0.40 & 0.47 \\
\hline Medical days & 1.7 & 1.3 & 0.35 & 0.29 \\
\hline \multicolumn{5}{|l|}{ Postweaning (42 to $56 \mathrm{~d}$ ) } \\
\hline Starter intake, kg/d & 1.95 & 2.32 & 0.079 & 0.01 \\
\hline$A D G, k g / d$ & 0.88 & 0.96 & 0.050 & 0.09 \\
\hline Feed efficiency & 0.452 & 0.413 & 0.0418 & 0.35 \\
\hline Hip width change, $\mathrm{cm}$ & 1.7 & 2.0 & 0.15 & 0.05 \\
\hline BCS change & 0.0 & -0.1 & 0.04 & 0.47 \\
\hline Fecal score & 2.0 & 2.0 & 0.03 & 0.12 \\
\hline Abnormal fecal days & - & - & - & - \\
\hline Medical days & 0.05 & 0 & 0.20 & 0.83 \\
\hline \multicolumn{5}{|l|}{ Overall ( 0 to $56 \mathrm{~d}$ ) } \\
\hline Milk replacer intake, $\mathrm{kg} / \mathrm{d}$ & 0.47 & 0.47 & - & - \\
\hline Starter intake, kg/d & 0.74 & 0.91 & 0.066 & 0.01 \\
\hline$A D G, k g / d$ & 0.57 & 0.65 & 0.027 & 0.01 \\
\hline Feed efficiency & 0.459 & 0.473 & 0.0214 & 0.54 \\
\hline Hip width change, $\mathrm{cm}$ & 4.0 & 4.5 & 0.24 & 0.02 \\
\hline BCS change & 0.1 & 0.2 & 0.06 & 0.14 \\
\hline Fecal score & 2.1 & 2.1 & 0.02 & 0.7 \\
\hline Abnormal fecal days & 2.0 & 2.3 & 0.46 & 0.53 \\
\hline Medical days & 1.8 & 1.4 & 0.41 & 0.31 \\
\hline
\end{tabular}

'Zuprevo (Merck Animal Health, Summit, NJ).

${ }^{2} \mathrm{BCS}$ : 1 - to 5 -point system with 1 being thin and 5 being obese, modified from Wildman et al. (1982).

${ }^{3}$ Feed efficiency was calculated as gain divided by the sum of milk replacer and starter intake. ${ }^{4}$ Feces were scored daily using a 1-to- 5 scale with 1 being normal and 5 being watery.

${ }^{5}$ Days with fecal scores of 3 or greater. 
Table 3. Performance of calves from 2 to 4 mo of age ( $56 \mathrm{~d}$ of data) that had not been treated (CON) or had been treated (TIL) with Zuprevo (4 mg of tildipirosin/kg of BW) ${ }^{1}$ in trial 1 , phase 2 and trial 2

\begin{tabular}{lcccc} 
Item & CON & TIL & SEM & P value \\
\hline Trial 1, phase 2 & & & & \\
Initial BW, kg & 74.5 & 78.4 & 2.49 & 0.16 \\
Final BW, kg & 122.3 & 133.7 & 5.26 & 0.06 \\
Initial hip width, cm & 21.2 & 21.8 & 0.28 & 0.07 \\
Final hip width, cm & 25.3 & 26.3 & 0.31 & 0.01 \\
Initial BCS & 2.3 & 2.4 & 0.05 & 0.25 \\
Final BCS & 2.6 & 2.7 & 0.07 & 0.25 \\
DMI, kg/d & 3.17 & 3.345 & 0.124 & 0.19 \\
DMI, \% BW & 3.25 & 3.16 & 0.17 & 0.60 \\
ADG, kg/d & 0.86 & 0.99 & 0.056 & 0.04 \\
Feed efficiency & 0.276 & 0.304 & 0.0216 & 0.22 \\
Hip width change, cm & 4.1 & 4.6 & 0.19 & 0.04 \\
BCS change & 0.3 & 0.3 & 0.05 & 0.46 \\
Trial 2 & & & & \\
Initial BW, kg & 72.1 & 70.2 & 1.73 & 0.44 \\
Final BW, kg & 119.1 & 123.4 & 2.41 & 0.23 \\
Initial hip width, cm & 20.4 & 20.4 & 0.31 & 1.00 \\
Final hip width, cm & 24.6 & 25.3 & 0.28 & 0.10 \\
Initial BCS & 2.3 & 2.3 & 0.042 & 0.48 \\
Final BCS & 2.7 & 2.6 & 0.055 & 0.19 \\
DMI, kg/d & 2.85 & 2.73 & 0.082 & 0.35 \\
DMI, \% BW & 2.93 & 2.85 & 0.055 & 0.35 \\
ADG, kg/d & 0.84 & 0.95 & 0.023 & 0.01 \\
Feed efficiency, G:F & 0.29 & 0.32 & 0.010 & 0.04 \\
Hip width change, cm & 4.1 & 4.8 & 0.13 & 0.003 \\
BCS change & 0.3 & 0.3 & 0.064 & 0.47 \\
\hline
\end{tabular}

${ }^{1}$ In trial 1, Zuprevo (Merck Animal Health, Summit, NJ) was administered near birth and 42 $\mathrm{d}$ later at weaning in phase 1 , with data collection for phase 2 beginning $14 \mathrm{~d}$ after weaning. In trial 2, in 2-mo-old calves, Zuprevo was administered once on $\mathrm{d} 0$ in calves that had been weaned for $14 \mathrm{~d}$.

${ }^{2} \mathrm{BCS}$ : 1 - to 5 -point system with 1 being thin and 5 being obese, modified from Wildman et al. (1982).

${ }^{3}$ Feed efficiency was calculated as gain divided by DMI.

CON from 3 d to 4 mo of age (Hill et al., 2017). In the trials by Stanton et al. (2010, 2013), healthy calves experienced improved BW and structural growth in the first 3 mo of age when metaphylactically administered TUL. Growth experienced in the first 3 mo of life appeared to be maintained to approximately $1 \mathrm{yr}$ of age in the study by Stanton et al. (2012). Because our calves appeared healthy and the medical treatments of CON calves were so low, number of medical treatments for disease were not affected by TIL, but improvements in BW and structural growth were realized.

\section{IMPLICATIONS}

Metaphylactic treatment of dairy calves with tildipirosin at $4 \mathrm{mg} / \mathrm{kg}$ of BW resulted in approximately $13 \%$ more BW and hip width gain in transported Holstein calves from 0 to 4 mo of age. In general, calves in the trial were healthy, and few calves were treated for respiratory and enteric disease.

\section{ACKNOWLEDGMENTS}

This research was fully funded by Provimi (Brookville, $\mathrm{OH})$.

\section{LITERATURE CITED}

Amrine, D. E., B. J. White, R. L. Larson, and D. A. Mosier. 2014. Pulmonary lesions and clinical disease response to Mannheimia haemolytica challenge 10 days following administration of tildipirosin or tulathromycin. J. Anim. Sci. 92:311-319.

Bartram, D. J., H. Moyaert, B. H. Vanimisetti, C. P. Ramage, D. Reddick, and M. R. Stegemann. 2016. Comparative efficacy of tulathro- 
mycin and tildipirosin for the treatment of experimental Mycoplasma bovis infection in calves. Vet. Med. Sci. 2:170-178.

Confer, A. W., T. W. Snider, J. D. Taylor, M. Montelongo, and N. J. Sorensen. 2016. Clinical disease and lung lesions in calves experimentally inoculated with Histophilus somni five days after metaphylactic administration of tildipirosin or tulathromycin. Am. J. Vet. Res. $77: 358-366$

FASS. 2010. Guide for the Care and Use of Agricultural Animals in Agricultural Research and Teaching. 3rd ed. FASS Inc., Champaign, IL.

Hill, T. M., J. D. Quigley, H. G. Bateman II, J. M. Aldrich, and R. L. Schlotterbeck. 2016. Source of carbohydrate and metabolizable lysine and methionine in the diet of recently weaned dairy calves on digestion and growth. J. Dairy Sci. 99:2788-2796.

Hill, T. M., J. D. Quigley, F. X. Suarez-Mena, T. S. Dennis, and R. L. Schlotterbeck. 2017. Case study: Control of bovine respiratory disease in dairy calves with tulathromycin and effect on calf health and performance from 0 to 4 months of age. Prof. Anim. Sci. 33:498-503.

Hulbert, L. E., and S. J. Moisá. 2016. Stress, immunity, and the management of calves. J. Dairy Sci. 99:3199-3216.

Kertz, A. F., and H. Chester-Jones. 2004. Invited Review: Guidelines for measuring and reporting calf and heifer experimental data. J. Dairy Sci. 87:3577-3580.

Menge, M., M. Rose, C. Bohland, E. Zschiesche, S. Klip, W. Metz, M. Allan, R. Ropke, and M. Nurnberger. 2012. Pharmacokinetics of tildipirosin in bovine plasma, lung tissue, and bronchial fluid (from live, non-anesthetized cattle). J. Vet. Pharmacol. Ther. 35:550-559.

Stanton, A. L., D. F. Kelton, S. J. LeBlanc, S. T. Millman, J. Wormuth, R. T. Dingwell, and K. E. Leslie. 2010. The effect of treatment with long-acting antibiotic at postweaning movement on respiratory disease and on growth in commercial dairy calves. J. Dairy Sci. 93:574-581

Stanton, A. L., D. F. Kelton, S. J. LeBlanc, J. Wormuth, L. K. Fox, and K. E. Leslie. 2012. The effect of respiratory disease and a preventative antibiotic treatment on growth, survival, age at first calving, and milk production of dairy heifers. J. Dairy Sci. 95:4950-4960.
Stanton, A. L., D. F. Kelton, S. J. LeBlanc, J. Wormuth, L. K. Fox, and K. E. Leslie. 2013. Effects of tulathromycin on incidence of various diseases and growth of young heifers. J. Am. Vet. Med. Assoc. 243:267-276

Svensson, C., K. Lundborg, U. Emanuelson, and S. O. Olsson. 2003. Morbidity in Swedish dairy calves from birth to 90 days of age and individual calf-level risk factors for infectious diseases. Prev. Vet. Med. 58:179-197.

USDA-APHIS (USDA-Animal and Plant Health Inspection Service). 1999. Part III: Health management and biosecurity in U.S. feedlots. No. N336.1200 USDA-APHIS-VS-CEAH, Fort Collins, CO. Accessed Aug. 29, 2016. https://www.aphis.usda.gov/animal_health/nahms/ feedlot/downloads/feedlot99/Feedlot99_dr_PartIII.pdf.

USDA-APHIS (USDA-Animal and Plant Health Inspection Service). 2009. Dairy 2007, Part IV: Reference of dairy cattle health and management practices in the United States, 2007. USDA-APHIS-VSCEAH, Fort Collins, CO. Accessed Aug. 29, 2016. http://www.aphis .usda.gov/animal_health/nahms/dairy/downloads/dairy07/Dairy07 dr_PartIV.pdf.

Weese, J. S. 2006. Prudent Use of Antimicrobials. Antimicrobial Therapy in Veterinary Medicine. 4th ed. S. Giguère, J. F. Prescott, J. D. Baggot, R. D. Walker, and P. M. Dowling, ed. Blackwell Publ., Ames, IA.

Weese, J. S., S. Giguere, L. Guardabassi, P. S. Morley, M. Papich, D. R. Ricciuto, and J. E. Sykes. 2015. ACVIM consensus statement on therapeutic antimicrobial use in animals and antimicrobial resistance. J. Vet. Intern. Med. 29:487-498.

Wildman, E. E., G. M. Jones, P. E. Wagner, R. L. Bowman, H. F. Troutt Jr., and T. N. Lesch. 1982. A dairy cow body condition scoring system and its relationship to selected production characteristics. J. Dairy Sci. 65:495-501.

Yates, W. D. 1982. A review of infectious bovine rhinotracheitis, shipping fever pneumonia and viral-bacterial synergism in respiratory disease of cattle. Can. J. Comp. Med. 46:225-263. 